\title{
Patient satisfaction with the endoscopy experience and willingness to return in a central Canadian health region
}

\author{
Russell Loftus MD1 , Zoann Nugent PhD ${ }^{1,2,3}$, Lesley A Graff PhD ${ }^{4}$, Frederick Schumacher BEng MSc IS ${ }^{1}$, \\ Charles N Bernstein MD ${ }^{1,2}$, Harminder Singh MD MPH ${ }^{1,2,5}$
}

\begin{abstract}
R Loftus, Z Nugent, LA Graff, F Schumacher, CN Bernstein, $\mathrm{H}$ Singh. Patient satisfaction with the endoscopy experience and willingness to return in a central Canadian health region. Can J Gastroenterol 2013;27(5):259-266.
\end{abstract}

OBJECTIVE: Patient experiences with endoscopy visits within a large central Canadian health region were evaluated to determine the relationship between the visit experience and the patients' willingness to return for future endoscopy, and to identify the factors associated with patients' willingness to return.

METHODS: A self-report survey was distributed to 1200 consecutive individuals undergoing an upper and/or lower gastrointestinal endoscopy at any one of the six hospital-based endoscopy facilities in the region. The Spearman correlation coefficient was used to assess the association between the patients' overall rating of the visits and willingness to return for repeat procedures under similar medical circumstances. Logistic regression analyses were performed to identify the factors associated with willingness to return for repeat endoscopy and overall satisfaction (rating) of the visit.

RESULTS: A total of 529 (44\%) individuals returned the questionnaire, with $45 \%$ rating the visit as excellent and 56\% indicating they were extremely likely to return for repeat endoscopy. There was a low moderate correlation between overall rating of the visit and patients' willingness to return for repeat endoscopy $(r=0.30)$. The factors independently associated with patient willingness to return for repeat endoscopy included perceived technical skills of the endoscopists (OR 2.7 [95\% CI 1.3 to 5.5]), absence of pain during the procedure (OR 2.2 [95\% CI 1.3 to 3.6]) and history of previous endoscopy (OR 2.4 [95\% CI 1.4 to 4.1]). In contrast, the independent factors associated with the overall rating of the visit included information provided pre- and postprocedure, wait time before and on the day of the visit, and the physical environment.

CONCLUSIONS: To facilitate patient return for needed endoscopy, it is important to assess patients' willingness to return because positive behavioural intent is not simply a function of satisfaction with the visit.

Key Words: Endoscopy; Patient-centred care; Patient satisfaction

Cndoscopic examination continues to be the gold standard for exam-

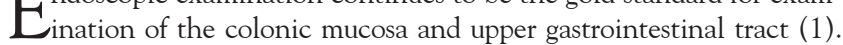
The indications for endoscopy are extensive for prevention (eg, colorectal cancer screening) as well as diagnostics and therapeutics (eg, gastrointestinal bleeding). As colorectal cancer screening becomes more popular, the number of colonoscopies performed has increased accordingly (2). New therapeutic and diagnostic techniques, in addition to current standards of care, mean that endoscopy will continue to be paramount in the future care of gastroenterology patients.

In a health care environment of patient engagement, with 'patient as consumer' becoming more of a focus, patient satisfaction and

\author{
La satisfaction des patients envers l'expérience \\ d'endoscopie et la disposition à en subir d'autres \\ dans une région sanitaire du centre du Canada
}

OBJECTIF : Les chercheurs ont évalué les expériences des patients relativement aux rendez-vous d'endoscopie dans une grande région sanitaire du centre du Canada pour déterminer la relation entre l'expérience du rendez-vous et la disposition à subir d'autres endoscopies et pour déterminer les facteurs associés à cette disposition.

MÉTHODOLOGIE : Les chercheurs ont distribué un sondage d'autoévaluation à 1200 individus consécutifs qui subissaient une endoscopie gastro-intestinale supérieure ou inférieure à l'un des six établissements endoscopiques en milieu hospitalier de la région. Ils ont utilisé le coefficient de corrélation de Spearman pour évaluer l'association entre le classement global des rendez-vous par les patients et leur disposition à subir de nouveau l'intervention dans des situations médicales similaires. Ils ont effectué des analyses de régression logistique pour déterminer les facteurs associés à la disposition à subir d'autres endoscopies et (le classement de) la satisfaction globale envers le rendez-vous.

RÉSULTATS : Au total, 529 personnes (44\%) ont remis le questionnaire, dont $45 \%$ ont évalué le rendez-vous comme excellent, et $56 \%$ ont indiqué qu'ils étaient extrêmement susceptibles de revenir subir des endoscopies. On constatait une corrélation minime à modérée entre le classement global du rendez-vous et la disposition du patient à subir d'autres endoscopies $(r=0,30)$. Les facteurs indépendamment associés à cette disposition du patient incluaient l'habileté technique perçue de l'endoscopiste (RRR 2,7 [95 \% IC 1,3 à 5,5]), l'absence de douleur pendant l'intervention (RRR 2,2 [95 \% IC 1,3 à 3,6]) et des antécédents d'endoscopie (RRR 2,4 [95 \% IC 1,4 à 4,1]). Par contre, les facteurs indépendants associés au classement global du rendez-vous incluaient l'information fournie avant et après l'intervention, le temps d'attente avant le jour du rendez-vous et le jour même du rendez-vous et l'environnement physique.

CONCLUSIONS : Pour faciliter le retour du patient à une endoscopie exigée, il est important d'évaluer sa disposition à revenir parce qu'une intention positive n'est pas simplement fonction de la satisfaction à l'égard du rendez-vous.

experience have come under a higher level of scrutiny. Patient satisfaction has become an important outcome measure in and of itself (3). Patient feedback may lead to higher standards, improved endoscopist performance and accountability, enhanced risk management and a higher quality of care (4). Satisfied patients are more likely to comply with medication regimens, and continue using medical services and individual care providers (5). Nonadherence and changing providers is more often apparent among patients who are dissatisfied (6).

Patient satisfaction with endoscopy has been investigated over the past decade (4,7-9). Patient satisfaction was found to be associated with the personal manner of the endoscopy unit staff, length of time

\footnotetext{
${ }^{1}$ Internal Medicine, University of Manitoba; ${ }^{2}$ University of Manitoba IBD Clinical and Research Centre; ${ }^{3}$ CancerCare Manitoba, Department of

Epidemiology and Cancer Registry; ${ }^{4}$ Clinical Health Psychology; ${ }^{5}$ Community Health Sciences, University of Manitoba, Winnipeg, Manitoba

Correspondence: Dr Harminder Singh, Section of Gastroenterology, University of Manitoba, 805-715 McDermot Avenue, Winnipeg, Manitoba R3E 3P4.

Telephone 204-480-1311, fax 204-789-3972, e mail singh@cc.umanitoba.ca

Received for publication September 26, 2012. Accepted November 29, 2012
} 


\section{TABLE 1}

Description of respondent demographics, survey responses and chart information $(n=529)$

Background information

\section{und information}

Age, years

$<50$

50-60

137 (27)

$61-70$

$>70$

Sex

Male

Education

Did not finish high school

High school

College diploma or certificate

Undergraduate university degree

Graduate course work/Masters/PhD

Do not wish to state

Marital status

Married or common-law

Separated or divorced

Widowed

Single

148 (30)

145 (29)

$226(45)$

66 (13)

142 (28)

144 (29)

61 (12)

58 (12)

31 (6)

381 (76)

44 (9)

50 (10)

$30(6)$

Endoscopy information

Procedure

Gastroscopy

132 (26)

23 (5)

419 (83)

Colonoscopy

178 (34)

48 (10)

46 (9)

85 (17)

35 (7)

90 (18)

71 (14)

98 (20)

Other symptoms

Visit with endoscopist before the procedure

Yes

$278(58)$

Hospital site for the procedure

$\begin{array}{lr}\text { A } & 67(13) \\ \text { B } & 71(13) \\ \text { C } & 108(20) \\ \text { D } & 100(19) \\ \text { E } & 82(16) \\ \text { F } & 101(19)\end{array}$

Before procedure

Written information provided

Yes

$443(85)$

Written information answered

$\begin{array}{lc}\text { All questions } & 351(80) \\ \text { Some questions } & 69(16) \\ \text { Few questions } & 12(3) \\ \text { No questions } & 7(2) \\ \text { Quality of all information (written or verbal provided) } & \\ \text { Excellent } & 223(43) \\ \text { Very good } & 184(36) \\ \text { Good } & 65(13) \\ \text { Fair } & 20(4) \\ \text { Poor } & 7(1) \\ \text { No information provided } & 16(3)\end{array}$

TABLE 1 - CONTINUED

Description of respondent demographics, survey responses and chart information $(n=529)$

\begin{tabular}{lc}
\hline & $\mathbf{n}\left(\%^{*}\right)$ \\
\hline Satisfaction with wait time for the endoscopy appointment & \\
Excellent & $159(30)$ \\
Very good & $153(29)$ \\
Good & $110(21)$ \\
Fair & $54(10)$ \\
Poor & $49(9)$ \\
Wait time for endoscopy appointment & \\
$<2$ weeks & $49(10)$ \\
2 weeks to 2 months & $180(35)$ \\
3 to 6 months & $163(32)$ \\
7 to 12 months & $82(16)$ \\
$>12$ months & $39(8)$ \\
Satisfaction with preprocedure waiting area & \\
Excellent & $169(32)$ \\
Very good & $207(40)$ \\
Good & $108(21)$ \\
Fair & $29(6)$ \\
Poor & $11(2)$
\end{tabular}

Satisfaction with time spent at hospital before the procedure on the day of the procedure

Excellent 194 (37)

Very good 191 (37)

Good $\quad 99$ (19)

Fair $25(5)$

Poor 14 (3)

Personal manner of the support staff

Excellent $370(70)$

Very good 121 (23)

Good 26 (5)

Fair 6 (1)

Poor $2(0.4)$

During and following the procedure

Personal manner of the endoscopist

Excellent $373(72)$

Very good $112(22)$

Good 31 (6)

Fair $3(1)$

Poor $2(0.4)$

Technical skills of the endoscopist

377 (74)

Good $105(21)$

Fair $2(0.4)$

$\begin{array}{ll}\text { Poor } & 0(0)\end{array}$

Pain during the procedure (0 to 10 scale)

No pain (0) $293(56)$

$1-3 \quad 155$ (29)

4-6 $51(10)$

7-9 21 (4)

Unbearable (10) 7 (1)

Adequacy of the explanation of the performed procedure and the findings

Excellent 166 (33)

Very good 158 (31)

Good 113 (22)

Fair 38 (8)

Poor 31 (6) 
TABLE 1 - CONTINUED

Description of respondent demographics, survey responses and chart information $(n=529)$

n $(\% *)$

\begin{tabular}{lc}
\hline Chart information (total $\mathbf{n = 3 0 9 )}$ & \\
Medical specialty of the endoscopy physician & $3(1)$ \\
General practice & $213(69)$ \\
Surgery & $91(30)$ \\
Gastroenterology & \\
Dose of midazolam used, $\mathrm{mg}$ (colonoscopy only [n=217]) & $11(5)$ \\
$<3$ & $180(83)$ \\
$3-5$ & $26(12)$ \\
$>5$ & \\
Dose of fentanyl used, $\mu \mathrm{g}$ (colonoscopy only $[\mathrm{n}=212])$ & $5(2)$ \\
$<50$ & $194(92)$ \\
$50-100$ & $13(6)$ \\
$>100$ & \\
\hline *Percentages are based on the number of individuals responding to the specific
\end{tabular}

item in the survey questionnaire

devoted by the physician in explaining the procedure, rating of the environment of the endoscopy suite and pain control during the procedure. However, these studies demonstrated methodological limitations, including potential bias inherent to single-centre studies, which did not adjust for the effect of multiple concomitant factors and, instead, evaluated one factor at a time. These studies often did not consider important behavioural outcomes such as the patient's willingness to return if another endoscopy is needed. This is relevant because many patients require additional endoscopy to monitor treatment efficacy or disease progression such as dysplasia surveillance in inflammatory bowel disease (10). Other patients may require repeat colonoscopy if a polyp or other abnormality is noted during colorectal cancer case finding or screening colonoscopy (11). The relationship between satisfaction and subsequent behavioural intent regarding endoscopy has not been examined, and the factors that influence patients' willingness to repeat the procedure are largely unknown.

The purpose of the present study was to evaluate patient satisfaction with endoscopy within a large central Canadian health region (Winnipeg Regional Health Authority) to determine the relationship between patient satisfaction with their most recent endoscopy experience and their willingness to return for repeat future endoscopy; and to more broadly identify the factors that influence patients' stated willingness to return for repeat endoscopy in the future.

\section{METHODS}

\section{Setting}

Manitoba is a central Canadian province with a population of 1.25 million. Approximately two-thirds of the endoscopies in the province are performed in the capital city of Winnipeg. The majority (85\%) of the endoscopies performed in the city are conducted through the six hospitals and their affiliated endoscopy units, all of which are administered by a single regional health authority. In 2008, an endoscopy redesign initiative was introduced by the health region to streamline and standardize the delivery of the endoscopy services in the city. The current study was performed as a quality assessment and improvement project of this initiative.

Two hundred consecutive patients at each of the six sites $(n=1200)$ undergoing an outpatient upper and/or lower gastrointestinal endoscopy in the first four months of 2011 were invited to complete a survey regarding their endoscopy visit experience. Patients who agreed to participate were given the questionnaire package at the site, and asked to complete it at home and mail it back in the postage-paid, selfaddressed envelope that was provided. They were asked to complete it within $24 \mathrm{~h}$ to $72 \mathrm{~h}$, waiting for at least one day before answering the survey questions to minimize any potential amnestic effect of the benzodiazepines administered for sedation.
Corresponding hospital chart numbers of the study participants were recorded with the surveys at five of the six sites to link procedure information for analyses. Subsequently, information was extracted from hospital charts related to the dose of the agents used for sedation and the medical specialty of the endoscopist performing the procedure to determine the association, if any, of these factors with patient satisfaction and willingness to return for repeat future procedures.

The 28-item Patient Endoscopy Experience survey was based on a previously validated Group Health Association of America-9 (GHAA-9) patient satisfaction questionnaire recommended by the American Society for Gastrointestinal Endoscopy (12) and expanded to meet the quality review purposes. The items drawn directly from the GHAA-9 questionnaire included questions assessing rating of the wait at the endoscopy facility, personal manner of the endoscopic personnel and the endoscopist, technical skills of the endoscopist, adequacy of the information provided after the procedure and overall rating of the visit, using five-point response categories of excellent, very good, good, fair or poor. The additional items of interest in the survey related to the regional restructuring initiative and included questions on the actual wait time for the endoscopy appointment, information provided before the procedure and indications for the procedure and procedural pain levels.

Patient satisfaction with the visit was assessed using two questions: satisfaction with the procedure performed $(1=$ very dissatisfied to $5=$ very satisfied) and overall rating of the visit (five-point scale anchored by excellent and poor from the GHAA-9). Additionally, a more specific behaviourally based outcome of the endoscopy experience patients' willingness to return - was evaluated by two items asking about the likelihood they would recommend future endoscopy to a friend and their own willingness to return for a future endoscopy. The response format for the latter two questions and the pain item was a numerical rating scale, with 0 representing no pain or, for the second question, not at all likely to return for repeat procedure. A score of 10 represented unbearable pain or extremely likely to undergo the procedure again, respectively. Finally, patient demographic information was also collected.

The main study outcome measures were selected to represent the overall rating of the visit and patients' own willingness to return for repeat endoscopy under similar medical circumstances because these were considered to be the most important measures in the survey for assessing overall satisfaction with the visit and patients' willingness to return for repeat endoscopy, respectively.

Hospital chart data were entered by an individual who was blinded to the survey responses. The survey data entry was automated, using scannable technology to minimize inaccuracies inherent in manual entry of data.

\section{Statistical analysis}

All analyses were performed on anonymized data. Standard descriptive analysis was performed to describe the responses. For descriptive purposes, the pain and willingness to return responses were each grouped into five categories $(0,1$ to 3,4 to 6,7 to 9 , and 10). Spearman correlations were used to determine associations between patient satisfaction and willingness to return.

Univariate and multivariate logistic regression analyses were performed to determine which factors were most relevant for the two primary outcomes of interest: overall patient rating of the visit, using the response of 'excellent' to define complete satisfaction versus not completely satisfied (all other responses); and willingness to return for repeat endoscopy under the same medical circumstances, using 10 to define completely willing versus not completely willing (responses 0 to 9). These definitions were used based on quality improvement theory, which advocates comparing outcomes to best practices and responses (13). However, in sensitivity analyses, a more liberal definition for the main outcomes of overall rating of the visit was used (excellent/very good rating versus good/fair/poor), and willingness to return (willing = 8 to 10 versus less willing 0 to 7 ) to assess the factors associated with these primary outcomes. 
TABLE 2

\section{Proportion of respondents who were satisfied and willing} to return for colonoscopy

\begin{tabular}{|c|c|}
\hline \multicolumn{2}{|c|}{ Satisfaction with the procedure } \\
\hline Very satisfied & 59 \\
\hline Satisfied & 27 \\
\hline Neutral & 4 \\
\hline Dissatisfied & 1 \\
\hline Very dissatisfied & 10 \\
\hline \multicolumn{2}{|l|}{ Overall rating of the visit } \\
\hline Excellent & 45 \\
\hline Very good & 40 \\
\hline Good & 13 \\
\hline Fair & 2 \\
\hline Poor & 1 \\
\hline \multicolumn{2}{|c|}{ Willingness to return for repeat procedure (0 to 10 scale) } \\
\hline Extremely likely (10) & 56 \\
\hline $7-9$ & 30 \\
\hline $4-6$ & 9 \\
\hline $1-3$ & 3 \\
\hline Not at all likely (0) & 2 \\
\hline \multicolumn{2}{|c|}{ Recommend a friend to undergo the procedure ( 0 to 10 scale) } \\
\hline Extremely likely (10) & 61 \\
\hline $7-9$ & 30 \\
\hline $4-6$ & 6 \\
\hline $1-3$ & 1 \\
\hline Not at all likely (0) & 2 \\
\hline
\end{tabular}

Data presented as \%

Variables included in the multivariate analyses were guided by the univariate results and likely clinical relevance: that is, the most clinically relevant factors were selected from each of the item categories of patient, procedure and endoscopic personnel-related factors and further aggregated the categories of responses - for example, excellent versus less than excellent rating of technical skills of the endoscopists. This was performed to avoid multicollinearity and to ensure that there was sufficient power (ie, 10 or more outcomes per variable category [14]). The analyses were performed using SAS version 9.2 (SAS Institute, USA).

The present study was performed as a quality assessment and improvement project. As such, it did not require formal approval from the local ethics board. It was reviewed and approved by the Winnipeg Regional Health Authority Endoscopy Services Redesign Committee. In addition, participants were duly informed of the nature and reasons for the study, and that participation was entirely voluntary.

\section{RESULTS}

Of the 1200 distributed surveys, 529 (44\%) were returned. Hospital chart numbers were available for 309 respondents to link to patientspecific information on sedation doses and the medical specialty of the endoscopist; therefore, some analyses were based on smaller numbers where indicated.
The demographic characteristics and a summary description of the survey responses are presented in Table 1 . Slightly more than one-half $(55 \%)$ of the respondents were women and $85 \%$ were $>50$ years of age. Fifty-three per cent had some postsecondary education.

The vast majority $(83 \%)$ underwent colonoscopy with or without gastroscopy. One-third were asymptomatic and underwent procedures for screening or surveillance for cancer or polyps. Approximately $23 \%$ had waited more than six months to undergo their procedure(s).

With regard to quality improvement initiatives related to communication, $85 \%$ reported having some written information provided to them before their procedures. However, fewer than one-half rated the quality of the information provided as 'excellent'. An even smaller proportion (one-third of respondents) rated the quality of the information provided to them after the procedures as excellent.

Overall, a majority $(59 \%)$ of the respondents were very satisfied with their procedure and nearly one-half $(45 \%)$ rated their visit as excellent (five of five). A majority (56\%) also reported that they were extremely likely (10 of 10) to return for repeat procedures under similar circumstances (Table 2).

There was a strong correlation $(\mathrm{r}=0.72)$ between the patients' own willingness to return for repeat endoscopy under similar medical circumstances and the likelihood of them advising a friend to undergo the procedure under the same medical circumstances (Table 3). There was a more modest relationship between satisfaction with the procedure and the overall rating of the visit $(\mathrm{r}=0.32)$. Similarly, there were modest correlations between these two measures of patient satisfaction and the behavioural intent items of patients' own willingness to return or for recommending the procedure to a friend.

Based on univariate logistic regression, an overall positive visit rating was associated with several factors, including a higher rating of the quality of the information provided preprocedure, satisfaction with the preprocedure wait time and waiting area, the personal manner of the support staff and the endoscopist, the perceived technical skills of the endoscopist, a lower level of pain during the procedure and the perception of adequate information provided after the procedure (Table 4). These variables were also significantly related to the patients' willingness to return for repeat endoscopy in the univariate analysis (Table 4). In addition, patients with the lowest level of formal education were less likely to return for repeat endoscopy.

Multivariate logistic regression analysis (Table 5) indicated the significant factors associated with the overall rating of the visit, once adjusting for age, sex and the other included factors. Variables that contributed to the overall visit rating included a higher rating of the quality of the information provided preprocedure, satisfaction with the wait time for the visit, preprocedure wait time on the day of the procedure, site of the procedure and adequacy of the information provided after the procedure (factor with the highest OR [6.39]).

Patients were more likely to be very willing to return for endoscopy if they had rated the technical skills of the endoscopist highly, if they experienced lower pain during the procedure, and if they had previous exposure to gastrointestinal endoscopy, after adjusting for the other factors.

In the sensitivity analysis, the factors associated with the more liberal definition of satisfaction as determined by the overall rating of the visit (excellent/very good rating versus good/fair/poor), and willingness to return (willing $=8$ to 10 versus less willing 0 to 7 ) were very similar to that of the main analysis (data not shown).

TABLE 3

Correlations among the patient satisfaction and willingness to return items

\begin{tabular}{|c|c|c|c|c|}
\hline & Satisfaction with the procedure & Overall rating of the visit & $\begin{array}{l}\text { Willingness to return for } \\
\text { repeat endoscopy }\end{array}$ & $\begin{array}{l}\text { Recommendation to a friend to } \\
\text { undergo the same procedure }\end{array}$ \\
\hline Satisfaction with the procedure & 1 & $r=0.32 ; P<0.0001$ & $r=0.26 ; P<0.0001$ & $r=0.25 ; P<0.0001$ \\
\hline Overall rating of the visit & $r=0.32 ; P<0.0001$ & 1 & $r=0.30 ; P<0.0001$ & $r=0.34 ; P<0.0001$ \\
\hline Willingness to return & $r=0.26 ; P<0.0001$ & $r=0.30 ; P<0.0001$ & 1 & $r=0.72 ; P<0.0001$ \\
\hline $\begin{array}{l}\text { Recommendation to a friend to } \\
\text { undergo the same procedure }\end{array}$ & $r=0.25 ; P<0.0001$ & $r=0.34 ; P<0.0001$ & $r=0.72 ; P<0.0001$ & 1 \\
\hline
\end{tabular}


TABLE 4

Factors associated with overall rating of the visit and willingness to return for repeat endoscopy (univariate analysis)

\begin{tabular}{|c|c|c|}
\hline & $\begin{array}{c}\text { Overall rating of } \\
\text { the visit }\end{array}$ & $\begin{array}{l}\text { Willingness to } \\
\text { return }\end{array}$ \\
\hline \multicolumn{3}{|l|}{ Background information } \\
\hline \multicolumn{3}{|l|}{ Age, years } \\
\hline$<50$ & $0.85(0.48-1.49)$ & $1.13(0.64-2.00)$ \\
\hline $50-60$ & $1.09(0.69-1.75)$ & $1.30(0.81-2.10)$ \\
\hline $61-70$ & Reference & \\
\hline$>70$ & $0.87(0.54-1.39)$ & $0.77(0.48-1.23)$ \\
\hline \multicolumn{3}{|l|}{ Sex } \\
\hline Male & $1.43(1.01-2.05)$ & $1.01(0.71-1.45)$ \\
\hline Female & Reference & \\
\hline \multicolumn{3}{|l|}{ Education } \\
\hline Did not finish high school & $1.37(0.75-2.50)$ & $0.53(0.29-0.97)$ \\
\hline High school & Reference & \\
\hline College diploma or certificate & $0.99(0.62-1.59)$ & $0.84(0.52-1.35)$ \\
\hline Undergraduate university degree & $1.09(0.59-2.00)$ & $0.58(0.32-1.07)$ \\
\hline $\begin{array}{l}\text { Graduate course work/Masters } \\
\text { degree /PhD }\end{array}$ & $1.20(0.65-2.21)$ & $0.88(0.47-1.66)$ \\
\hline \multicolumn{3}{|l|}{ Marital status } \\
\hline Married or common-law & Reference & \\
\hline Separated or divorced & $0.50(0.25-1.00)$ & $0.69(0.36-1.30)$ \\
\hline Widowed & $0.71(0.39-1.30)$ & $0.93(0.51-1.72)$ \\
\hline Single & $0.75(0.35-1.59)$ & $0.99(0.47-2.09)$ \\
\hline \multicolumn{3}{|l|}{ Endoscopy information } \\
\hline \multicolumn{3}{|l|}{ Procedure } \\
\hline Gastroscopy only & $0.63(0.37-1.06)$ & $0.93(0.56-1.55)$ \\
\hline Flexible sigmoidoscopy & $0.61(0.22-1.67)$ & $1.08(0.38-3.10)$ \\
\hline Colonoscopy only & Reference & \\
\hline Gastroscopy and colonoscopy & $0.83(0.47-1.47)$ & $0.65(0.36-1.14)$ \\
\hline \multicolumn{3}{|l|}{ Previous gastrointestinal endoscopy } \\
\hline Yes & $1.21(0.84-1.74)$ & $1.77(1.22-2.55)$ \\
\hline No & Reference & \\
\hline \multicolumn{3}{|l|}{ Indications for the procedure } \\
\hline Screening or surveillance & $1.26(0.87-1.83)$ & $1.44(0.99-2.1)$ \\
\hline Symptomatic & Reference & \\
\hline \multicolumn{3}{|c|}{ Visit with endoscopy physician before the procedure } \\
\hline Yes & $1.34(0.92-1.93)$ & $1.23(0.85-1.78)$ \\
\hline No & Reference & \\
\hline \multicolumn{3}{|l|}{ Hospital site for the procedure } \\
\hline A & $0.71(0.37-1.36)$ & $0.79(0.42-1.47)$ \\
\hline B & $1.63(0.88-2.99)$ & $0.91(0.49-1.69)$ \\
\hline C & $1.41(0.81-2.45)$ & $0.84(0.48-1.46)$ \\
\hline D & $1.14(0.63-2.05)$ & $1.42(0.77-2.61)$ \\
\hline E & $0.83(0.47-1.46)$ & $0.82(0.47-1.43)$ \\
\hline $\mathrm{F}$ & Reference & \\
\hline
\end{tabular}

Before procedure

Written information provided

\begin{tabular}{|c|c|c|}
\hline Yes & $1.77(1.07-2.94)$ & $0.78(0.47-1.27)$ \\
\hline No & Reference & \\
\hline \multicolumn{3}{|l|}{ Written information answered } \\
\hline All questions & Reference & \\
\hline Some questions & $0.40(0.24-0.66)$ & $0.56(0.34-0.92)$ \\
\hline Few questions & $0.25(0.05-1.23)$ & $0.91(0.24-3.44)$ \\
\hline No questions & * & $0.54(0.12-2.47)$ \\
\hline \multicolumn{3}{|c|}{ Quality of all information (written or verbal provided) } \\
\hline Excellent & Reference & \\
\hline Very good & $0.15(0.10-0.23)$ & $0.48(0.32-0.72)$ \\
\hline Good & $0.05(0.02-0.11)$ & $0.36(0.2-0.65)$ \\
\hline Fair & * & $0.47(0.18-1.21)$ \\
\hline Poor & $0.15(0.03-0.78)$ & $2.61(0.3-22.71)$ \\
\hline No information provided & $0.22(0.08-0.64)$ & $1.04(0.34-3.16)$ \\
\hline
\end{tabular}

TABLE 4 - CONTINUED

Factors associated with overall rating of the visit and willingness to return for repeat endoscopy (univariate analysis)

\begin{tabular}{|c|c|c|}
\hline & $\begin{array}{l}\text { Overall rating of } \\
\text { the visit }\end{array}$ & $\begin{array}{c}\text { Willingness to } \\
\text { return }\end{array}$ \\
\hline \multicolumn{3}{|c|}{ Satisfaction with wait time for endoscopy appointment } \\
\hline Excellent & Reference & \\
\hline Very good & $0.19(0.12-0.32)$ & $0.42(0.26-0.68)$ \\
\hline Good & $0.10(0.06-0.18)$ & $0.26(0.15-0.44)$ \\
\hline Fair & $0.16(0.08-0.32)$ & $0.42(0.22-0.81)$ \\
\hline Poor & $0.15(0.07-0.31)$ & $0.49(0.25-0.97)$ \\
\hline \multicolumn{3}{|c|}{ Satisfaction with preprocedure waiting area } \\
\hline Excellent & Reference & \\
\hline Very good & $0.13(0.08-0.20)$ & $0.40(0.26-0.61)$ \\
\hline Good & $0.04(0.02-0.08)$ & $0.36(0.21-0.61)$ \\
\hline Fair & $0.03(0.01-0.09)$ & $0.44(0.19-1.00)$ \\
\hline Poor & $0.05(0.01-0.25)$ & $0.34(0.10-1.16)$ \\
\hline
\end{tabular}

Satisfaction with time spent at hospital before the procedure on the day of the procedure

$\begin{array}{lcc}\text { Excellent } & \text { Reference } & \\ \text { Very good } & \mathbf{0 . 1 3}(\mathbf{0 . 0 8}-0.21) & \mathbf{0 . 3 7}(\mathbf{0 . 2 4 - 0 . 5 6 )} \\ \text { Good } & \mathbf{0 . 0 2 ( 0 . 0 1 - 0 . 0 5 )} & \mathbf{0 . 3 1}(\mathbf{0 . 1 9 - 0 . 5 3 )} \\ \text { Fair } & \mathbf{0 . 0 5 ( 0 . 0 2 - 0 . 1 5 )} & \mathbf{0 . 2 9}(\mathbf{0 . 1 2}-0.68) \\ \text { Poor } & * & 0.53(0.18-1.61) \\ \text { Personal manner of the support staff } & & \\ \text { Excellent } & \text { Reference } & \\ \text { Very good } & \mathbf{0 . 0 6 ( 0 . 0 3 - 0 . 1 1 )} & \mathbf{0 . 2 3}(\mathbf{0 . 1 4 - 0 . 3 5 )} \\ \text { Good } & * & \mathbf{0 . 1 5}(\mathbf{0 . 0 6 - 0 . 4 2 )} \\ \text { Fair/Poor } & * & 0.69(0.15-3.12)\end{array}$

During and following the procedure

Personal manner of the endoscopist

$\begin{array}{lcc}\text { Excellent } & \text { Reference } & \\ \text { Very good } & 0.04(0.01-0.17) & 0.04(0.01-0.17) \\ \text { Good } & 0.17(0.04-0.73) & 0.17(0.04-0.73)\end{array}$

Fair/poor

Technical skills of the endoscopist

Excellent

Very good $\quad 0.07(0.03-0.14) \quad 0.20(0.12-0.33)$

Good/fair/poor $\quad 0.03(0.01-0.23) \quad 0.20(0.08-0.53)$

Adequacy of the explanation of the performed procedure and the findings

Excellent Reference

Very good $\quad 0.19(0.11-0.31) \quad 0.45(0.28-0.71)$

Good $\quad 0.04(0.02-0.07) \quad 0.24(0.14-0.41)$

Fair $\quad \mathbf{0 . 0 4}(\mathbf{0 . 0 1}-\mathbf{0 . 1 1}) \quad 0.66(0.30-1.42)$

Poor $\quad 0.02(0.01-0.07) \quad 0.58(0.26-1.30)$

Pain during the procedure

No pain

Any reported pain

$1.52(1.07-2.17) \quad 2.08(1.46-2.98)$

Reference

\section{Chart information}

Medical specialty of the endoscopy physician

$\begin{array}{lcc}\text { Surgery } & 0.88(0.53-1.45) & 1.05(0.63-1.73) \\ \text { Gastroenterology } & \text { Reference } & \end{array}$

Dose of midazolam used for colonoscopy, $\mathrm{mg}$

\begin{tabular}{lcc}
$<3$ & $1.51(0.45-5.14)$ & $0.51(0.15-1.75)$ \\
$3-5$ & Reference & \\
$>5$ & $0.76(0.31-1.82)$ & $0.62(0.26-1.45)$ \\
Dose of fentanyl used for colonoscopy, $\mu \mathrm{g}$ & \\
$<50$ & $0.82(0.13-5.01)$ & $0.15(0.02-1.38)$ \\
$50-100$ & Reference & \\
$>100$ & $0.61(0.18-2.11)$ & $0.43(0.13-1.41)$ \\
\hline
\end{tabular}

Data presented as OR $(95 \% \mathrm{Cl})$. Bolded values indicate statistically significant findings. *The number of patients with the outcome was small in this category of the variable and, hence, the respective category was not included in the regression analysis 


\section{TABLE 5}

Predictors of overall satisfaction, willingness to return for repeat endoscopy and reported absence of pain during colonoscopy (multivariate analysis)

\begin{tabular}{lcc}
\hline Predictor & $\begin{array}{c}\text { Overall rating of } \\
\text { the visit }\end{array}$ & $\begin{array}{c}\text { Willingness to } \\
\text { return }\end{array}$ \\
\hline $\begin{array}{l}\text { Age, years } \\
<50\end{array}$ & $1.45(0.49-4.32)$ & $2.25(0.99-5.09)$ \\
$50-60$ & $1.33(0.56-3.16)$ & $1.45(0.76-2.79)$ \\
$61-70$ & Reference & \\
$>70$ & $0.71(0.29-1.74)$ & $0.81(0.42-1.58)$ \\
Sex & $1.11(0.56-2.23)$ & $0.81(0.49-1.37)$ \\
Male & Reference & \\
Female & & \\
Education & $2.99(0.98-9.14)$ & $0.95(0.43-2.08)$ \\
Did not finish high school & Reference & \\
High school or more & &
\end{tabular}

Marital status

Married or common-law

Not partnered

Reference

Procedure

\begin{tabular}{|c|c|c|}
\hline Gastroscopy only & $0.78(0.26-2.35)$ & $1.07(0.50-2.31)$ \\
\hline Colonoscopy & \multicolumn{2}{|l|}{ Reference } \\
\hline \multicolumn{3}{|c|}{ vious gastrointestinal endoscopy } \\
\hline Yes & $1.25(0.63-2.47)$ & $2.42(1.44-4.09)$ \\
\hline No & Reference & \\
\hline
\end{tabular}

Indications for the procedure

Screening or surveillance

Symptomatic

$1.33(0.65-2.72) \quad 1.44(0.84-2.47)$ Reference

Visit with endoscopist before the procedure

Yes
No
Site
A
B
C
D
E
F

$0.69(0.33-1.43)$

Reference

No

Site

A

$0.14(0.04-0.44)$

$0.43(0.16-1.19)$

$0.79(0.23-2.69)$

$0.53(0.16-1.69)$

$0.79(0.27-2.38)$

Reference

Quality of all information (written or verbal provided)

Excellent

3.81 (1.95-7.46)

Less than excellent

Reference

Satisfaction with wait time for endoscopy appointment

Excellent $\quad 3.61(1.70-7.69)$

Less than excellent

Reference

Satisfaction with preprocedure waiting area

Excellent

3.04 (1.44-6.42)

Reference

Less than excellent

Satisfaction with time spent at hospital before the procedure on the day of the procedure

\section{Excellent}

$1.76(0.93-3.31)$

Less than excellent

Reference

Personal manner of the support staff

Excellent

Less than excellent

2.86 (0.97-8.39)

$1.85(0.91-3.76)$

Technical skills of the endoscopist

Excellent

Reference

Less than excellent

3.03 (0.92-9.91)

$2.66(1.28-5.51)$

Reference

Adequacy of the explanation of the performed procedure and the findings

Excellent

6.39 (3.05-13.40)

$1.37(0.77-2.45)$

Less than excellent

Reference

Pain

No pain

$1.36(0.69-2.66)$

$2.15(1.29-3.58)$
4.87 (2.28-10.39)

Any reported pain Reference

Data presented as OR (95\% Cl). Bolded values indicate statistically significant findings
There was a site difference, such that one of the endoscopy sites had a lower overall rating of the visit compared with the other sites (in the model with adjustment for patient demographic factors, indications of the procedures and history of previous endoscopy), and had the lowest satisfaction rating with the preprocedure wait time and with the waiting area (data not shown for detailed site analysis to protect anonymity of the sites).

\section{DISCUSSION}

Results of the present study suggest that satisfaction with endoscopy visit (as determined by overall rating of the visit) and the behavioural intention to return are different conceptually and practically, and may need to be assessed separately to understand the patient experience with endoscopy and the impact on future endoscopies. We found that the independent factors associated with willingness to return for repeat endoscopy were different than those for overall rating of the visit, and included perceived technical skills of the endoscopist, previous exposure to gastrointestinal endoscopy and lower recall of pain during the procedure.

Although overall patient rating of the visits is an important aspect of patient satisfaction, we believe willingness to return for endoscopy may be viewed as a more important end point of patient-centred care because it will likely have bearing on future compliance with needed endoscopy. We found that the perceived technical skills of the endoscopist was the factor with the highest independent association (approximately threefold higher likelihood) with willingness to return for repeat endoscopy. Future studies should evaluate the factors determining patients' perception of endoscopist skills and whether patient perception, in fact, correlates with the actual performance indicators for procedural quality such as cecal intubation during colonoscopy. In addition, because patient perception will likely drive future decision making, it will be even more important to devise measures to ensure that the patient perspective is aligned with the actual technical skills of the endoscopists. Qualitative methods may be particularly informative to evaluate the patient experience in this regard. While it can be argued that actual technical skills are more important than perceived skill of the endoscopist, our data suggest that an important aspect of patients' willingness to return includes ensuring there is a positive experience interpersonally in the endoscopy unit and the endoscopist's reputation for excellence.

Our study suggests that pain control is very significant to patients because it was a major factor in the willingness to return for endoscopy. Flexible sigmoidoscopy to screen for colorectal cancers is being rapidly adopted in Europe, where it is often performed without sedation; wider acceptance in Canada may require facilities for sedation. A United States study reported increased pain with lower sedation use during endoscopy (9); therefore, some consideration needs to be given to an appropriate level of sedation to facilitate a more positive endoscopy experience. Level of sedation was not addressed in our study, but would be an appropriate factor to investigate in future research. In North America, patient expectations with regard to discomfort during endoscopic procedures are believed to be different than in Europe.

It is concerning that individuals with the lowest education level indicated a lower willingness to return for repeat endoscopy in the analysis without adjustment for factors such as perceived adequacy of information provided before and after the procedures. Such differences may enhance inequities in delivery and outcomes of health care, even in systems such as ours with universal health care and no direct financial impediments (ie, no deductibles or premiums for health care). This finding suggests that patient education regarding endoscopy needs to be readily available and should target potential misconceptions around the endoscopy experience, with some attention devoted to appropriate reading levels.

From a quality perspective, the findings that the personal manner of the support staff, physical surroundings and the adequacy of the information provided before and after the procedures were significantly related to overall rating of the visit provides some direction for 
potential improvements, and suggest some direction for follow-up qualitative evaluation (eg, focus group). A previous single-centre study also reported that positive interaction with nurses and support staff and explanation of the procedure was linked to higher patient satisfaction (7). These findings could explain why there is such a limited correlation between satisfaction with the procedure and the overall rating of the visit. It appears that procedural satisfaction is merely a part of the overall satisfaction, and this underlines the importance of effective communication, information sharing and pleasant physical environment of the endoscopy unit. While Canadian facilities in public hospitals may have limited financing with regard to the physical surroundings that are not within the control of the endosocpists, the adequacy of the information provided before and after the procedures is under the direction of the endoscopists and could be better incorporated into the regular processes at the sites.

Our health region has recently standardized the information provided and is working to ensure that all patients receive adequate information before and after the procedures. The findings from the present study provide an impetus to re-evaluate the information packages developed to date given the modest support for the quality of the information, because fewer than one-third rated as excellent the information provided postprocedure, and only $40 \%$ rated the preprocedure information as excellent. Our study has also generated a closer examination of the site with the lowest patient satisfaction rating by the regional Endoscopy Redesign Initiative Committee.

A central intake process for endoscopy has been initiated in the region, which has the potential to more uniformly distribute relevant endoscopy information and coordinate access. A practice recommendation arising from the present study is to provide all patients with a patient-friendly version of their endoscopy report to address the clear dissatisfaction with postprocedure communication found in the present study. The impact of such interventions on patient ratings of the visit and willingness to return for endoscopy will need to be determined in the future.

There is an increasing emphasis on patient-centred care and patient satisfaction. It has been suggested that these are related but somewhat different concepts. The Institute of Medicine defines patient centredness as "providing care that is respectful of and representative to individual patient preferences, needs, and values and ensuring that patient values guide all clinical decisions", whereas 'patient satisfaction', has its roots in consumer marketing, and is a measure of how services or products of a company meet or exceed the anticipated expectations of the customer" (15). We believe ensuring willingness to return for necessary repeat procedures is an important component of patient-centred care. Overall rating of the visits is likely more so a measure of patient satisfaction. Future research is needed to assess the relationship between the expressed behavioural intention and the actual behaviour, assessing the rate of return for those who were more willing and less willing to return depending on their procedure experience.

Our results should be considered in the context of the study's strengths and limitations. We assessed multisite 'usual practice' processes. A number of studies have considered patient willingness to return to repeat the procedure $(16-22)$, but all ask the question with regard to either type of imaging modality used $(16,17)$, the use of sedation $(18,19,21,22)$ or patient-controlled sedation $(20)$. To our knowledge, the present study was the first to evaluate the relationship of patient willingness to return for endoscopy and patient overall rating of the visit in a multicentre, usual clinical practice. We had a good response rate of $44 \%$. We used machine-readable questionnaires, which reduced the potential risk of errors related to manual entry of data. However, similar to other survey studies, the study was limited by potential bias of those who chose to participate, as well as potential recall bias. The generalizability of our findings to the for-profit/private health care settings will need to be determined in additional studies. That is, patient satisfaction is the difference between expectations of an encounter and the actual experience, and the expectations may be higher when patients are directly paying for the service. We acknowledge that the stated intention for future procedure does not necessarily translate to action, which should be assessed by long-term studies on the actual return for the needed procedures. Future studies should explore the effect of factors that were not included in the current study, such as such as endoscopic diagnosis, occurrence of immediate complications, nurse rating of the comfort during the procedure and difficulty in performing the procedure, but may still be relevant. A much larger sample size (ie, number of respondents) would be required to study the effect of the relatively rare events such as diagnosis of colon cancer and/or complications on patient satisfaction and willingness to return for repeat endoscopy.

\section{CONCLUSION}

The current study suggests that the patients' willingness to return for repeat endoscopy should be assessed separately from satisfaction in patient experience surveys. Patient experience surveys can prompt important changes in the endoscopy units such as ours and provide valuable direction for improved patient-centred care.

DISCLOSURES/ACKNOWLEDGEMENTS: There are no conflicts of interest for any of the authors. Dr Singh was supported, in part, by an ACG Junior Faculty Development Grant. Dr Bernstein holds the University of Manitoba Bingham Chair in Gastroenterology. Drs Singh and Graff were involved in the study concept and design; acquisition of data; analysis and interpretation of data; and critical revision of the manuscript for important intellectual content. Dr Nugent was involved in the analysis of data and critical revision of the manuscript for important intellectual content. Dr Bernstein was involved in the interpretation of the data and critical revision of the manuscript for important intellectual content. Mr Schumacher was involved in acquisition of data and critical revision of the manuscript for important intellectual content. Dr Loftus was involved in acquisition of data; analysis and interpretation of data and critical revision of the manuscript for important intellectual content.

\section{REFERENCES}

1. Rex DK, Petrini JL, Baron TH, et al. Quality indicators for colonoscopy. Am J Gastroenterol 2006;101:873-85.

2. El-Serag HB, Petersen L, Hampel H, Richardson P, Cooper G. The use of screening colonoscopy for patients cared for by the Department of Veterans Affairs. Arch Intern Med 2006; 166:2202-8.

3. Larsen IK, Grotmol T, Bretthauer M, et al. Continuous evaluation of patient satisfaction in endoscopy centres. Scand J Gastroenterol 2002;37:850-5.

4. Ko HH, Zhang H, Telford JJ, Enns R. Factors influencing patient satisfaction when undergoing endoscopic procedures. Gastrointest Endosc 2009;69:883-91, quiz.

5. Aharony L, Strasser S. Patient satisfaction: What we know about and what we still need to explore. Med Care Rev 1993;50:49-79.

6. Schutz SM, Lee JG, Schmitt CM, Almon M, Baillie J. Clues to patient dissatisfaction with conscious sedation for colonoscopy. Am J Gastroenterol 1994;89:1476-9.

7. Yacavone RF, Locke GR III, Gostout CJ, Rockwood TH, Thieling S, Zinsmeister AR. Factors influencing patient satisfaction with GI endoscopy. Gastrointest Endosc 2001;53:703-10.

8. Pena LR, Mardini HE, Nickl NJ. Development of an instrument to assess and predict satisfaction and poor tolerance among patients undergoing endoscopic procedures. Dig Dis Sci 2005;50:1860-71.

9. Eckardt AJ, Swales C, Bhattacharya K, et al. Open access colonoscopy in the training setting: Which factors affect patient satisfaction and pain? Endoscopy 2008;40:98-105.

10. Eaden JA, Mayberry JF. Guidelines for screening and surveillance of asymptomatic colorectal cancer in patients with inflammatory bowel disease. Gut 2002;(51 Suppl 5):V10-V12.

11. Winawer SJ, Zauber AG, Fletcher RH, et al. Guidelines for colonoscopy surveillance after polypectomy: A consensus update by the US Multi-Society Task Force on Colorectal Cancer and the American Cancer Society. Gastroenterology 2006;130:1872-85.

12. Quality and outcomes assessment in gastrointestinal endoscopy American Society for Gastrointestinal Endoscopy. Gastrointest Endosc 2000;52:827-30. 
13. Rubin HR, Gandek B, Rogers WH, Kosinski M, McHorney CA, Ware JE Jr. Patients' ratings of outpatient visits in different practice settings. Results from the Medical Outcomes Study. JAMA 1993;270:835-40.

14. Peduzzi P, Concato J, Kemper E, Holford TR, Feinstein AR. A simulation study of the number of events per variable in logistic regression analysis. J Clin Epidemiol 1996;49:1373-9.

15. Kupfer JM, Bond EU. Patient satisfaction and patient-centered care: Necessary but not equal. JAMA 2012;308:139-40.

16. Nicholson FB, Korman MG. Acceptance of flexible sigmoidoscopy and colonoscopy for screening and surveillance in colorectal cancer prevention. J Med Screen 2005;12:89-95.

17. Bosworth HB, Rockey DC, Paulson EK, et al. Prospective comparison of patient experience with colon imaging tests. Am J Med 2006;119:791-9.
18. Takahashi Y, Tanaka H, Kinjo M, Sakumoto K. Sedation-free colonoscopy. Dis Colon Rectum 2005;48:855-9.

19. Yoruk G, Aksoz K, Unsal B, et al. Colonoscopy without sedation. Turk J Gastroenterol 2003;14:59-63.

20. Lee DW, Chan AC, Wong SK, Li AC, Sze TS, Chung SC.

The safety, feasibility, and acceptability of patient-controlled sedation for colonoscopy: Prospective study. Hong Kong Med J 2004;10:84-8.

21. Hoffman MS, Butler TW, Shaver T. Colonoscopy without sedation. J Clin Gastroenterol 1998;26:279-82.

22. Rex DK, Imperiale TF, Portish V. Patients willing to try colonoscopy without sedation: Associated clinical factors and results of a randomized controlled trial. Gastrointest Endosc 1999;49:554-9. 


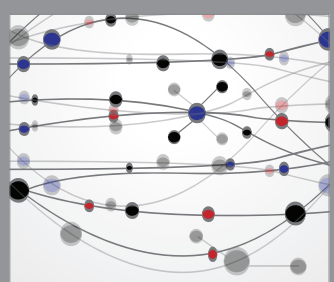

The Scientific World Journal
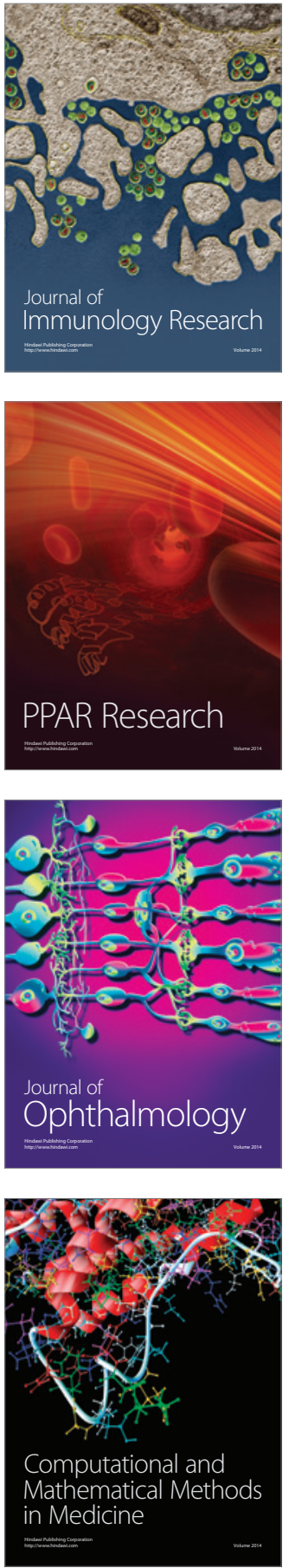

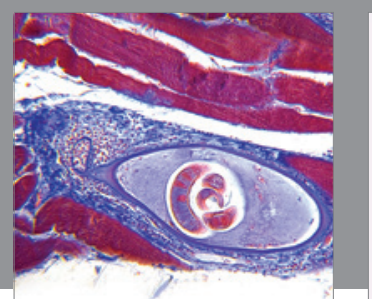

Gastroenterology Research and Practice

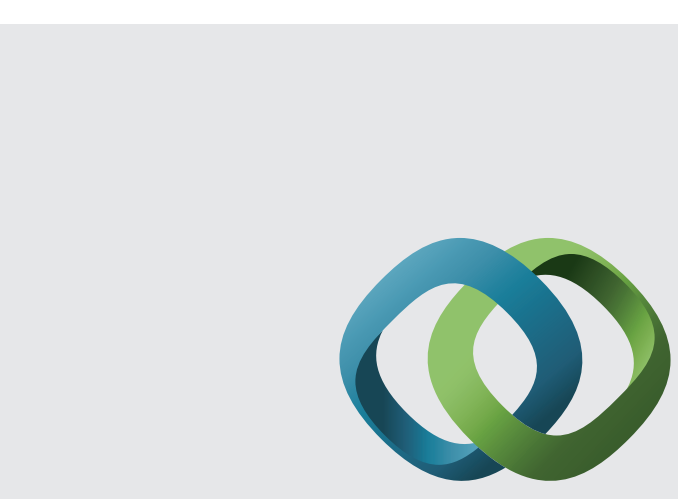

\section{Hindawi}

Submit your manuscripts at

http://www.hindawi.com
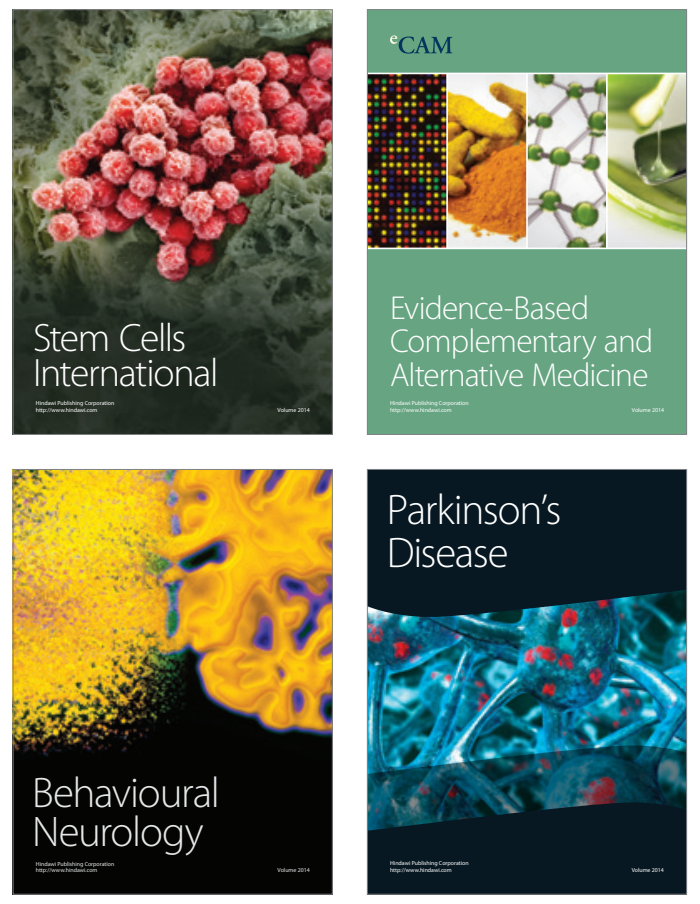
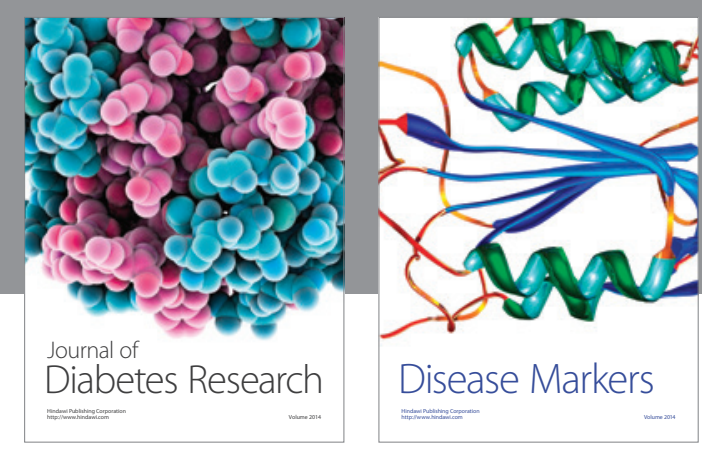

Disease Markers
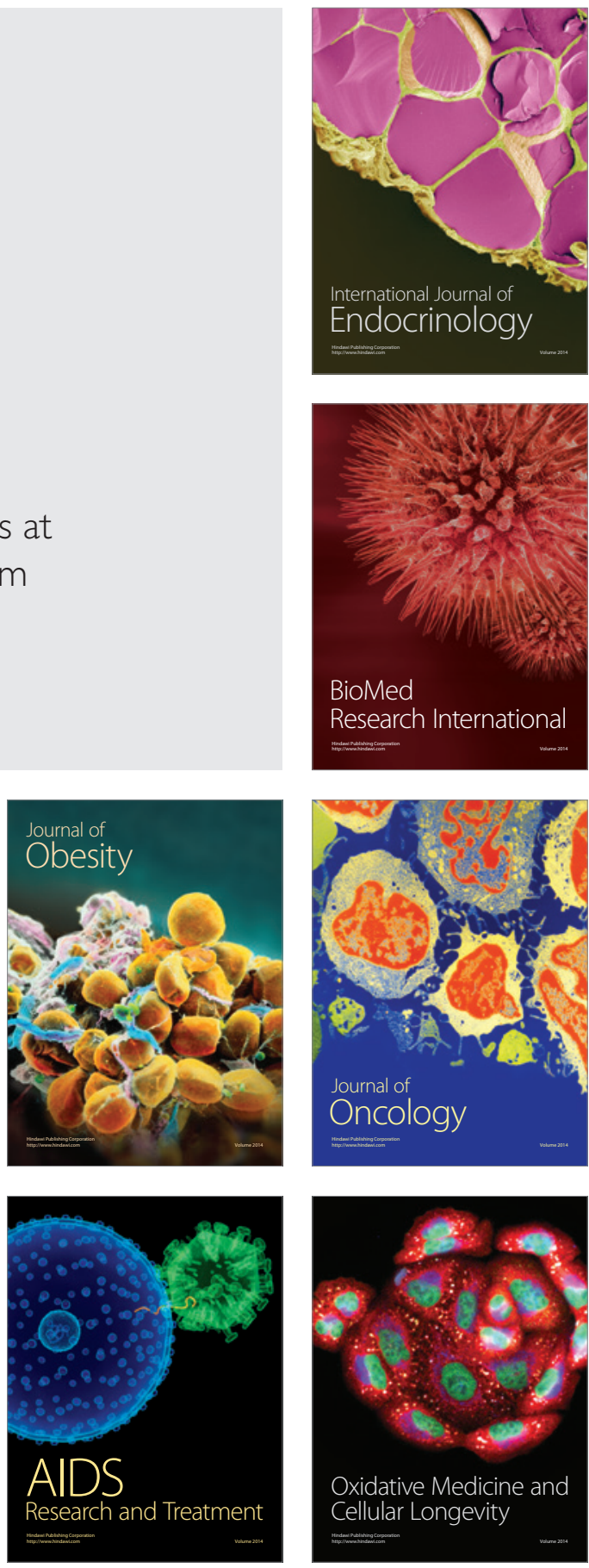